\title{
Cardiac Beat Accepted
}

National Cancer Institute

\section{Source}

National Cancer Institute. Cardiac Beat Accepted. NCI Thesaurus. Code C69190.

An indication that a heart beat was detected and accepted as conforming to the measurement standards. 